\title{
Estimating the cost and effectiveness of different STI management strategies for sex workers in Madagascar
}

Horizons Program

Follow this and additional works at: https://knowledgecommons.popcouncil.org/departments_sbsr-hiv

Part of the Diseases Commons, and the International Public Health Commons How does access to this work benefit you? Let us know!

\section{Recommended Citation}

"Estimating the cost and effectiveness of different STI management strategies for sex workers in Madagascar," Horizons Research Summary. Washington, DC: Population Council, 2002. 


\section{Hgrizons}

\section{Estimating the Cost and Effectiveness OF DifFERENT STI MANAGEMENT STRATEGIES FOR SEX WORKERS IN}

MADAGASCAR

Tn Madagascar, the prevalence of sexually transmitted infections (STIs) is a serious public health problem, particularly among sex worker populations. In 2000 , Horizons, in partnership with Family Health International (FHI) and the Madagascar Ministry of Health, conducted a study in three cities that found approximately two-thirds of the female sex workers in the sample had an STI, although few were infected with HIV. Since the link between the presence of STIs and transmission of HIV has been well established, affordable strategies to manage STIs among sex workers need to be developed.

Study investigators also conducted an assessment of STI management practices in health facilities in two urban areas of Madagascar. They found that health practitioners were using a syndromic approach to manage STIs (that is, treating for STIs if the patient presents with symptoms and signs associated with specific infections). While this approach may be appropriate for the management of certain STIs (such as genital ulcer disease) in the general population, it is less appropriate for sex workers who may have multiple, often asymptomatic infections, all of which may not be captured through this method of diagnosis. If practitioners were to

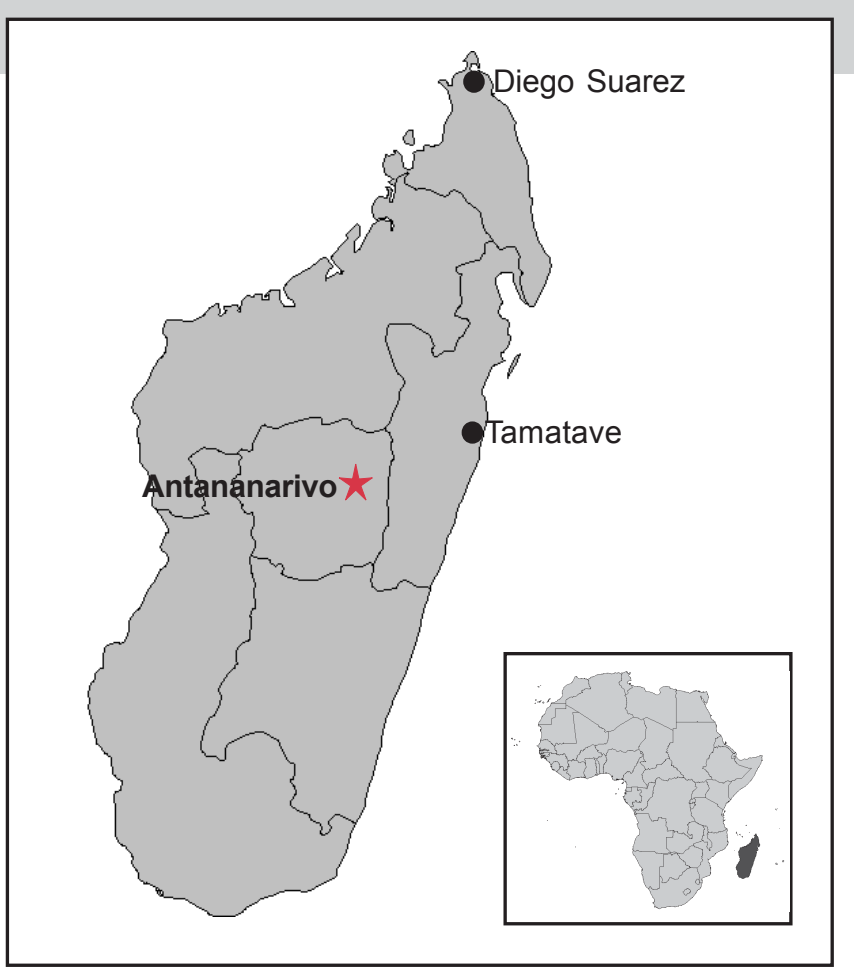

diagnose STIs with laboratory tests, however, medical visits would become prohibitively expensive and time-consuming.

Hence, the researchers proposed examining another method of diagnosing STIs in sex workers. They developed a risk profile for various STIs based on characteristics of women that present with each STI, such as age, number of partners, symptoms, and so on. The investigators hypothesized that a risk assessment tool using these profiles would result in more appropriate and effective STI treatment for sex workers.

This summary presents a cost-effectiveness analysis of different strategies to manage STIs among sex workers in Madagascar. 


\section{Study Design}

First, the researchers evaluated the cost-effectiveness of different approaches to screening and treatment of STIs in sex workers: standard syndromic management, a combination of syndromic management and risk assessment, and use of laboratory evaluation in combination with risk assessment.

Second, the investigators

Horizons conducts global operations research to improve HIV/AIDS prevention, care, and support programs. Horizons is implemented by the Population Council in partnership with the International Center for Research on Women (ICRW), the Program for Appropriate Technology in Health (PATH), the International HIV/AIDS Alliance, Tulane University, Family Health International, and Johns Hopkins University. month period. This model allows the user to explore "what if" questions regarding the method used to diagnose an infection and the timing of follow-up assessments for sex workers in Madagascar. Separate models were developed for syphilis, cervical infections (gonorrhea and/or chlamydia), and vaginal infections (trichomoniasis and/or bacterial vaginosis $^{2}$.

To calculate the costs, the researchers estimated the value of resources used in different types of STI management, such as health practitioners' time, supplies, laboratory tests, and drugs.

The researchers also modeled the expected reduction of STI prevalence among the sex workers using the different methods of diagnosis and various follow-up times. The probability of reinfection of sex workers with any STI was estimated on the basis of observed reinfection rates, reported sexual behavior data, the epidemiology of STIs, the effectiveness of diagnostic methods, and the effectiveness of treatments.
The investigators modeled the expected costs and benefits in terms of reduced STI prevalence of different approaches to managing STIs over a 12 -

\section{Study Methods}

\begin{tabular}{|c|c|c|c|c|}
\hline Algorithm & $\begin{array}{l}\text { Predicted } \\
\text { prevalence at } 12 \\
\text { months post- } \\
\text { intervention }\end{array}$ & $\begin{array}{l}\text { Incremental } \\
\text { annual cost in } \\
\text { MGF (\$US) }\end{array}$ & $\begin{array}{l}\text { Cost per } \\
\text { percentage } \\
\text { decrease in } \\
\text { prevalence in } \\
\text { MGF (\$US) }\end{array}$ & $\begin{array}{l}\text { Incremental cost } \\
\text { per person in } \\
\text { MGF (\$US) }\end{array}$ \\
\hline Syndromic management (SM) & $30.2 \%$ & --- & --- & ---- \\
\hline $\begin{array}{l}\text { SM and risk assessment (RA) } \\
\text { every } 30 \text { days }\end{array}$ & $17.3 \%$ & $\begin{array}{c}12,945,288 \\
(\$ 1,951)\end{array}$ & $\begin{array}{l}1,002,437 \\
(\$ 151)\end{array}$ & $\begin{array}{l}13,291 \\
(\$ 2.00)\end{array}$ \\
\hline SM and RA every 90 days & $16.9 \%$ & $\begin{array}{l}7,986,857 \\
(\$ 1,204)\end{array}$ & $\begin{array}{l}598,825 \\
(\$ 90)\end{array}$ & $\begin{array}{r}8,200 \\
(\$ 1.24)\end{array}$ \\
\hline $\begin{array}{l}\text { Risk assessment w/laboratory } \\
\text { every } 30 \text { days }\end{array}$ & $17.6 \%$ & $\begin{array}{c}53,228,017 \\
(\$ 8,021)\end{array}$ & $\begin{array}{l}4,227,724 \\
(\$ 637)\end{array}$ & $\begin{array}{l}54,649 \\
(\$ 8.24)\end{array}$ \\
\hline $\begin{array}{l}\text { Risk assessment w/laboratory } \\
\text { every } 90 \text { days }\end{array}$ & $17.3 \%$ & $\begin{array}{c}32,989,137 \\
(\$ 4,971)\end{array}$ & $\begin{array}{l}2,552,376 \\
(\$ 385)\end{array}$ & $\begin{array}{l}33,870 \\
(\$ 5.10)\end{array}$ \\
\hline
\end{tabular}

Note: MGF = Malagasy franc; 6,636 MGF = US\$1. 
Key Findings

A combination of syndromic management and risk assessment can be a cost-effective method for decision-making. Table 1 shows the incremental costs and effectiveness of using three methods to diagnose and manage cervical infections (gonorrhea and/or chlamydia): syndromic management, syndromic management with risk assessment, and laboratory evaluation and risk assessment. The cost of decreasing the prevalence of cervical infection by one percent using a risk assessment is almost one-fourth the cost of using a combination of risk assessment and a laboratory test. The use of laboratory diagnosis increases the annual cost of STI management on the basis of a risk assessment by 300 percent, although the effectiveness is about the same. Even more dramatic results were found for the treatment of trichomoniasis and bacterial vaginosis, since using laboratory results for followup assessments for these conditions increases annual costs per sex worker by 488 percent.

Frequent follow-up visits result in higher costs, but STI prevalence would remain the same. The investigators estimated the costs and effectiveness of requiring follow-up visits every 30 days compared to every 90 days. In all cases, the more frequent follow-up resulted in higher costs per sex worker, ranging from 11.8 percent higher for syphilis to 62 percent higher for cervical infections. Surprisingly, the prevalence at the end of 12 months was predicted to be higher (range: 2 percent higher for cervical infection to 10.8 percent higher for trichomoniasis and bacterial vaginosis) among sex workers seen more frequently than those seen less often. This happens because more sex workers may be lost to follow-up when asked to return more frequently. While initially there may be a performance advantage to more frequent assessment, as sex workers stop returning this early advantage is lost, as seen in Figure 1.
Figure 1 Predicted prevalence of cervical infection among sex workers by intervention

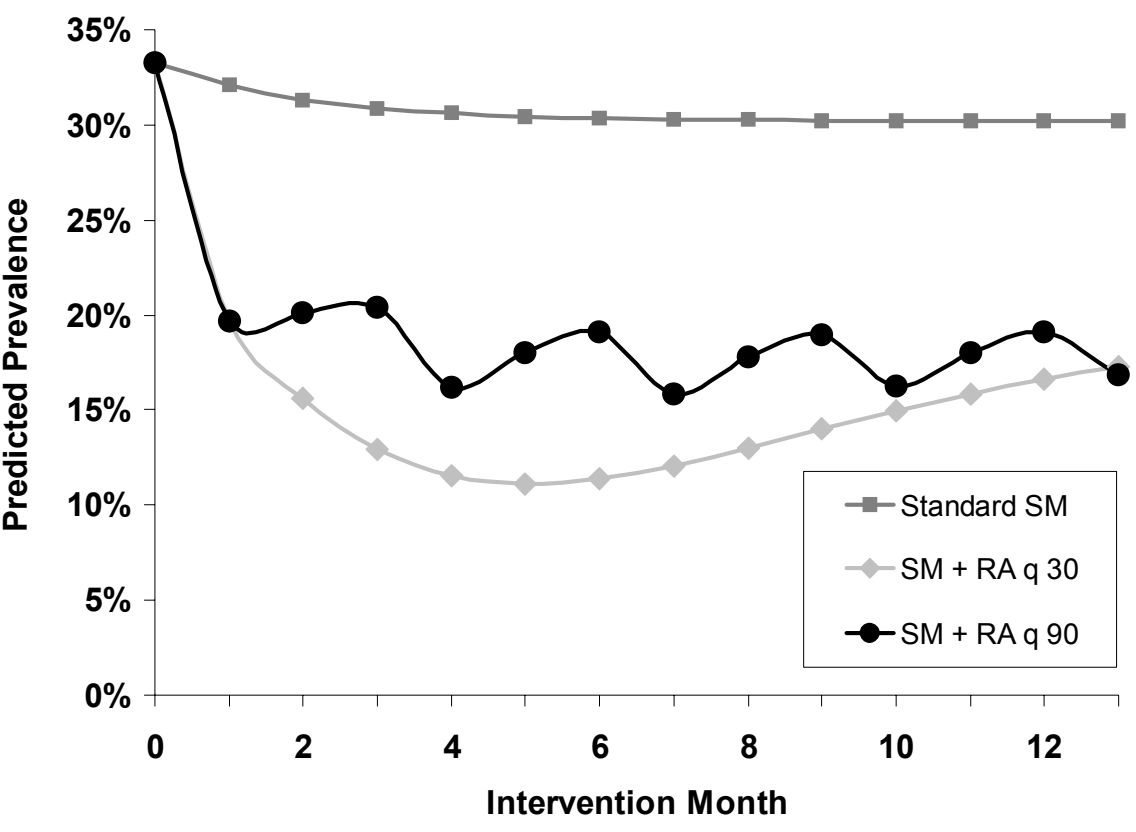

\section{Application of Findings}

In May 2001, the research team presented its findings at a participatory planning workshop in Antananarivo, Madagascar, with Ministry of Health officials, service providers, and sex workers. The ability to look at the tradeoffs between alternatives engaged the participants and helped the group reach consensus as to which policy would be pursued.

At the end of the meeting, the Ministry of Health developed an affordable management protocol for sex workers with STIs. The protocol calls for a clinician to employ a combination of diagnostic techniques for management of STIs in sex workers: laboratory test for syphilis; presumptive treatment for gonorrhea, chlamydia, and trichomoniasis on initial visit; and use of a combination of syndromic management and risk assessment for treatment of gonorrhea, chlamydia, and trichomoniasis on follow-up visits, and for chancroid and bacterial vaginosis for all visits. The participants also made the decision to change the country's policy to have sex workers return every 90 days for follow-up rather than every 30 days, as originally stipulated. 


\section{Conclusion}

The study indicates that a modeled costeffectiveness analysis can provide useful and sometimes unexpected findings about the use of various approaches to the management of STIs, which in turn has implications for HIV prevention. In this case, an affordable strategy for screening and treatment of a particularly vulnerable group was developed with information on cost-effectiveness and with involvement of the intended audience.

The findings also illustrate that a tension exists between cost and effectiveness: More effective methods of diagnosing cases of STI are more costly. The use of laboratory tests would be the most effective way of diagnosing STIs in sex workers, but their high costs are often not affordable. Instead, other less costly but less effective options were considered. The study found that the most cost-effective approach to the management of STIs in most cases is to make treatment decisions based on a combination of syndromic management and risk assessment, rather than to rely on any but the most simple laboratory tests. For a disease such as syphilis, for which a cheap and relatively simple laboratory test is available, use of that test represents the most cost-effective way of managing infections.

The findings on costs and effectiveness differed for each STI, indicating that disaggregated analysis is necessary in studies of costeffectiveness of STI management. ?

\footnotetext{
${ }^{1}$ Behets, Frieda et al. "Evidence-based Treatment Guidelines for Sexually Transmitted Infections Developed with and for Female Sex Workers." Submitted for publication.

${ }^{2}$ Although bacterial vaginosis is an endogenous infection and not sexually transmitted, it was included as part of the modeling exercise on STI management strategies.
}

Study investigators were Rick Homan and Kathleen van Damme of Family Health International; Frieda M.T. Behets and Kristi McClamroch of the University of North Carolina-Chapel Hill; Désiré Rasamilalao, Justin Ranjalahy Rasolofomanana, and Andry Rasamindrakotroka of the Madagascar Ministry of Health; and Johannes van Dam of Horizons/Population Council.

The authors would like to acknowledge the enthusiastic collaboration from the Ministry of Health and various other stakeholders from the public and nongovernmental sectors in conducting the research, the collaboration from the women attending the clinics and especially those who collaborated in the final workshop, and last, but not least, the support from the U.S. Agency for International Development, both in Madagascar and in Washington, DC.

\section{Hgrizons \\ Population Council}

Population Council/Horizons

Communications Unit

4301 Connecticut Avenue, NW

Suite 280

Washington, DC 20008
Tel: 202-237-9400

Fax: 202-237-8410

horizons@pcdc.org

www.popcouncil.org/horizons
USAID This publication was made possible through support provided by the Global Bureau of Health/HIV-AIDS, U.S. Agency for International Development, under the terms of Award No. HRN-A-00-97-00012-00. The opinions expressed herein are those of the authors and do not necessarily reflect the views of the U.S. Agency for International Development. 